\title{
Control of erythroid cell production via caspase- mediated cleavage of transcription factor SCL/Tal-1
}

\author{
A Zeuner ${ }^{1,2}$, A Eramo ${ }^{1}$, U Testa ${ }^{1}$, N Felli ${ }^{1}$, E Pelosi ${ }^{1}$, G Mariani ${ }^{1}$, \\ SM Srinivasula ${ }^{3}$, ES Alnemri ${ }^{3}$, G Condorelli $^{3}$, C Peschle $^{1,3}$ and \\ R De Maria*1,2 \\ 1 Department of Hematology and Oncology, Istituto Superiore di Sanità, Rome \\ 00161, Italy \\ 2 Department of Experimental Oncology, Istituto Oncologico del Mediterraneo, \\ Catania 95029, Italy \\ ${ }^{3}$ Kimmel Cancer Center, Thomas Jefferson University, Philadelphia, PA 19107, \\ USA \\ * Corresponding author: Ruggero De Maria; Laboratory of Hematology and \\ Oncology, Istituto Superiore di Sanità, viale Regina Elena 299, Rome 00161, \\ Italy. Tel: +39 0649903121; Fax: 39 0649387087; E-mail: rdemaria@ @in.it
}

Received 17.1.03; revised 13.3.03; accepted 14.3.03

Edited by RA Knight

\begin{abstract}
SCL/Tal-1 is a helix-loop-helix (HLH) transcription factor required for blood cell development, whose abnormal expression is responsible for induction of T-cell acute lymphoblastic leukemia. We show here that SCL/Tal-1 is a key target of caspases in developing erythroblasts. SCL/Tal-1 degradation occurred rapidly after caspase activation and preceded the cleavage of the major erythroid transcription factor GATA-1. Expression of a caspase-resistant SCL/Tal-1 in erythroid progenitors was able to prevent amplification of caspase activation, GATA-1 degradation and impaired erythropoiesis induced by growth factor deprivation or death receptor triggering. The potent proerythropoietic activity of uncleavable SCL/Tal-1 was clearly evident in the absence of erythropoietin, a condition that did not allow survival of normal erythroid cells or expansion of erythroblasts expressing caspase-resistant GATA-1. In the absence of erythropoietin, cells expressing caspase-resistant SCL/Tal-1 maintain high levels of $\mathrm{Bcl}-\mathrm{X}_{\mathrm{L}}$, which inhibits amplification of the caspase cascade and mediates protection from apoptosis. Thus, SCL/TAL-1 is a survival factor for erythroid cells, whereas caspase-mediated cleavage of SCL/Tal-1 results in amplification of caspase activation, GATA-1 degradation and impaired erythropoiesis.

Cell Death and Differentiation (2003) 10, 905-913. doi:10.1038/ sj.cdd. 4401255
\end{abstract}

Keywords: hematopoiesis; transcription factors; CD95 (APO-1; Fas); stem cell leukemia; E proteins

Abbreviations: Epo, erythropoietin; HLH, helix-loop-helix; GFP, green fluorescent protein.

\section{Introduction}

Erythropoiesis involves the sequential formation in the bone marrow of proerythroblasts and basophilic, polychromatophilic and orthochromatic erythroblasts, which extrude the nucleus and enter the circulation as mature red blood cells. ${ }^{1}$ Erythroid cell homeostasis is controlled by positive and negative signals that regulate survival, expansion and maturation of erythroid progenitors and precursors. Red blood cell production is inhibited by caspases, which induce degradation of the major erythroid transcription factor GATA-1 in late erythroid progenitors and early erythroblasts, followed by reversible growth and differentiation arrest or apoptosis. ${ }^{2,3}$ Survival of immature erythroid cells is promoted by erythropoietin (Epo), which cooperates with GATA-1 in sustaining the expression of $\mathrm{Bcl}-\mathrm{X}_{\mathrm{L}},{ }^{4} \mathrm{a} \mathrm{Bcl}-2$-related gene with antiapoptotic properties. ${ }^{5} \mathrm{Bcl}-\mathrm{X}_{\mathrm{L}}$ is regarded as a key survival factor for erythropoiesis, as suggested by the occurrence of massive apoptosis of fetal liver hematopoietic cells from bcl$X_{L}^{-l-}$ mice and by the inability of bcl- $X_{L}^{-/-}$embryonic stem cells to generate mature erythroblasts. ${ }^{4,6,7}$

Gene knockout studies have shown that GATA-1 is required for erythroid cell survival and maturation, ${ }^{8}$ while disruption of other erythroid transcription factors, such as LMO2/RBTN2 and SCL/Tal-1, results in early embryonic lethal anemia with complete failure of yolk sac hematopoiesis. ${ }^{9,10}$ These transcription factors interact to form transcriptional complexes essential for erythroid development. ${ }^{11}$

The SCL/Tal-1 gene was initially identified at the site of a $t(1 ; 14)(p 32 ; q 11)$ translocation breakpoint in a human stem cell line derived from a patient with $\mathrm{T}$-cell acute lymphoblastic leukemia (T-ALL). ${ }^{12}$ The SCL/Tal-1 gene product belongs to the basic helix-loop-helix (bHLH) family of transcription factors that comprises several proteins involved in the control of cell growth and differentiation. ${ }^{13,14}$ Like other tissuerestricted bHLH transcription factors, SCL/Tal-1 binds DNA as a heterodimer with the ubiquitously expressed $E$ proteins, which recognize the hexanucleotide sequence CANNTG found in a wide variety of eukaryotic transcriptional enhancers. $^{15-17}$

While absent in normal adult T lymphocytes, ${ }^{12}$ the SCL/Tal1 protein is constitutively expressed in the majority of T-ALL. ${ }^{18}$ In some cases, aberrant SCL/Tal-1 expression results from chromosomal translocations that juxtapose the SCL/Tal-1 gene with T-cell receptor regulatory elements. ${ }^{12,19,20}$ More commonly, the SCL/Tal-1 gene is activated as the result of a specific interstitial chromosomal deletion that replaces SCL/ Tal-1 regulatory elements with those of an upstream gene named sil. ${ }^{21-23}$ Direct evidence supporting the leukemogenic properties of SCL/Tal-1 has been obtained from studies in mice with enforced thymic expression of SCL/Tal-1. ${ }^{24} \mathrm{How}$ ever, since the highest transforming activity of SCL/Tal-1 is observed in concert with LMO1 or LMO2 overexpression, ${ }^{25,26}$ or in a $\mathrm{p} 53^{-/-}$background, ${ }^{24}$ it is likely that multiple genetic 
lesions cooperate in the genesis of T-cell malignancies. It is not clear whether SCL/Tal-1 acts through direct DNA binding or through interaction with other transcription factors. ${ }^{27}$ The latter mechanism seems responsible for the development of human and experimental T-cell malignancies, where the synergistic oncogenic activity of SCL/Tal-1 and LMO2/RBTN2 is mediated by the inactivation of $\mathrm{E}$ proteins and consequent silencing of genes implicated in tumor suppression and apoptosis. ${ }^{26,28,29}$

During embryonic development, SCL/Tal-1 is expressed in a variety of hematopoietic and nonhematopoietic cell types, ${ }^{27,30,31}$, whereas in normal adult tissues SCL/Tal-1 expression becomes restricted to hematopoietic and endothelial cells. ${ }^{32}$ In erythroid cells, SCL/Tal-1 is highly expressed throughout the maturation process and forms transcriptionally active heterodimers with E2A proteins, possibly participating in the activation of erythroid-specific genes. ${ }^{33}$ In fact, antisense oligomers to SCL/Tal-1 inhibit proliferation and self-renewal of erythroleukemia cells, and forced SCL/Tal-1 expression exerts a selective stimulatory effect on erythroid development of normal hematopoietic progenitors. ${ }^{34,35}$ Moreover, selective expression of SCL/Tal-1 in early hematopoietic progenitors is able to rescue myelopoiesis but not erythropoiesis in SCL/Tal- $1^{-1-}$ mice. ${ }^{36}$

This study was designed to evaluate the function of SCL/ Tal-1 in normal erythroid cells and its role during the negative regulation of erythropoiesis. Expression of a caspaseresistant form of SCL/Tal-1 led to a growth factor-independent survival and expansion of erythroid progenitor cells and sustained $\mathrm{Bcl}-\mathrm{X}_{\mathrm{L}}$ levels in Epo-deprived erythroblasts, suggesting that SCL/Tal-1 and its regulation by caspases play a critical role in the regulation of erythropoiesis.

\section{Results}

\section{SCL/Tal- 1 is cleaved by caspases in immature erythroblasts}

Death receptor stimulation of early erythroid precursors contributes to the physiological regulation of erythropoiesis. ${ }^{2,3,37}$ To determine whether SCL/Tal-1 expression is affected during this process, immature erythroid precursors grown in unilineage culture were treated with anti-CD95 and analyzed for transcription factor protein levels. Immunofluorescence labelling experiments showed that SCL/Tal-1 expression dramatically decreased in the vast majority of CD95treated erythroblasts after 1-day stimulation in the absence of the caspase inhibitor zVAD-fmk, while GATA-1 and GATA-2 levels were moderately affected (Figure 1a), indicating that caspase activation in erythroblasts results in early reduction of SCL/Tal-1 levels. Similarly, immunoblot analysis and quantitation showed a rapid SCL/Tal-1 downmodulation, which precedes substantial caspase- 3 activation, GATA-1 degradation and increase in GATA-2 levels by $12-24 \mathrm{~h}$ (Figure 1b,c). Caspase inhibitors prevented decline of SCL/Tal-1 levels and subsequent modulation of GATA transcription factors (Figure $1 \mathrm{~b}, \mathrm{c})$. While GATA-1 is degraded after caspase activation, GATA-2 expression increases, possibly as a result of the considerable reduction in the inhibitory activity of GATA-1. ${ }^{3,38}$ To investigate whether SCL/Tal-1 is a direct target of caspases, in vitro-translated $\left[{ }^{35}\right.$ S]methionine-labelled SCL/ Tal-1 was incubated with purified caspase-3, -7 and -8, as they have been previously found to be responsible for GATA-1 cleavage and negative regulation of erythropoiesis. ${ }^{3}$ All the three caspase were able to cleave SCL/Tal-1, as shown by the formation of two degradation fragments of $\sim 24$ and $\sim 20 \mathrm{kDa}$ (Figure 2a). To obtain SCL/Tal-1 mutants resistant to caspase-mediated cleavage, we mutated the aspartic acid at position 180 (EITD) and 296 (SSLD) to glutamic acid, generating a partially resistant mutant (SCL D180E) and a double mutant (SCL D180E/D296E) completely resistant to caspase-mediated cleavage (Figure $2 \mathrm{a}$ and data not shown). Since caspases cleave SCL/Tal-1 immediately before the basic region, producing a $\mathrm{C}$-terminal fragment containing the bHLH domain, we investigated whether this potentially active fragment was present in erythroblasts subjected to CD95 stimulation. Immunoblot analysis with an antibody specifically directed towards the bHLH domain of SCL/Tal-1 showed after caspase activation the formation of a $20 \mathrm{kDa}$ band that underwent rapid degradation (Figure $2 b$ ), ruling out the possibility that SCL/Tal-1 cleavage may produce transcriptionally active proteins.

\section{Expression of caspase-resistant SCL/Tal-1 overcomes CD95-mediated inhibition of erythropoiesis and prevents GATA-1 downmodulation}

We next investigated whether SCL/Tal-1 cleavage was involved in CD95-mediated inhibition of erythropoiesis. Wildtype and caspase-resistant SCL/Tal-1 were cloned in PINCO, a hybrid EBV/retroviral vector expressing the green fluorescent protein (GFP) as a selectable marker. Transfection of PINCO into the Phoenix amphotropic packaging cell line yields high-titer retroviral particles $\left(>10^{7}\right.$ colony forming units/ $\mathrm{ml}$ ) that can be used to infect $\mathrm{CD} 34^{+}$hematopoietic progenitor cells with an average efficiency of about $50 \% .{ }^{39} \mathrm{CD} 34^{+}$cells infected with the empty PINCO vector, with PINCO-SCL/Tal-1 or PINCO-SCL D180E/D296E (caspase-resistant SCL/Tal-1) were analyzed by flow cytometry and sorted on the basis of comparable GFP expression to obtain $100 \%$ pure populations of transduced cells expressing equal levels of exogenous genes. Immature erythroid cells expressing caspase-resistant SCL/Tal-1 were able to differentiate despite the inhibitory effect of CD95 stimulation (Figure 3a,b). By contrast, wild-type SCL/Tal-1 was scarcely effective in sustaining erythroid maturation in the presence of anti-CD95 agonistic antibody (Figure 3b). Moreover, expression of SCL D180E/D296E allowed expansion of erythroid progenitor cells stimulated with anti-CD95 agonistic antibody, which inhibits proliferation of cells transduced with empty vector or wild-type SCL/Tal-1 (Figure 3c). Taken together, these results suggest that SCL/ Tal-1 cleavage is a key event in death receptor-mediated inhibition of erythropoiesis.

GATA-1 expression is required for erythroid cell survival, differentiation and expansion. ${ }^{3,8}$ Since GATA-1 is downregulated after CD95 stimulation in erythroblasts, we measured GATA-1 levels in cells that were able to overcome the CD95-mediated inhibition through the expression of caspase- 
a

GATA-1

SCL
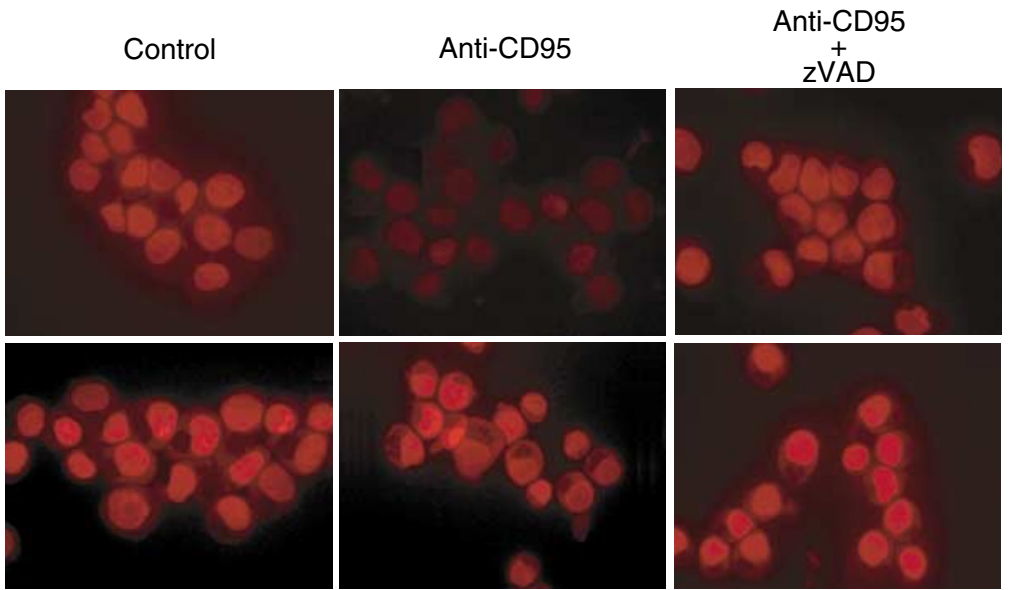

GATA-2
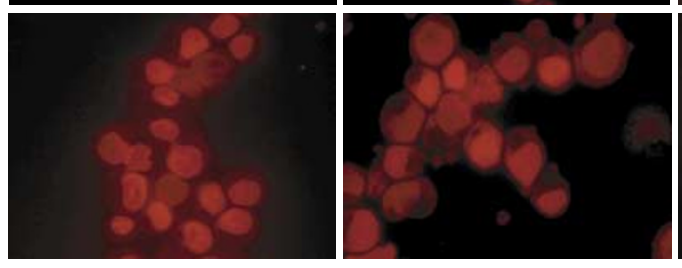

b

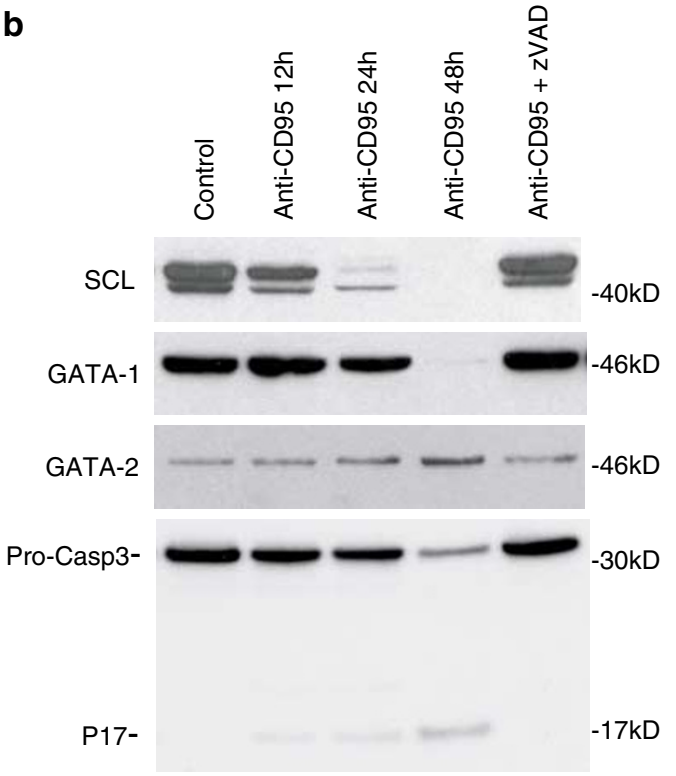

C $\square$ Anti-CD95 $12 \mathrm{~h}$ Anti-CD95 48h

- Anti-CD95 24h $\square$ Anti-CD95 + zVAD

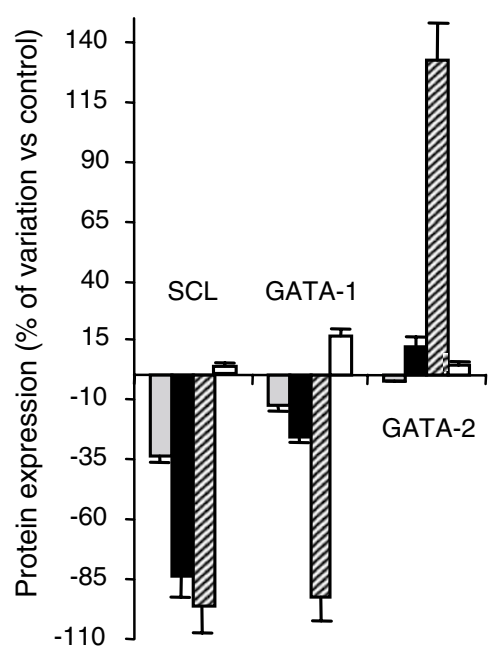

Figure $1 \mathrm{SCL} / \mathrm{Tal} 1$ is an early target of caspases in CD95-stimulated erythroblasts. (a) Immunofluorescence analysis for SCL/Tal-1, GATA-1 and GATA-2 of day-7 erythroblasts treated for $24 \mathrm{~h}$ with control lgM (left), anti-CD95 (middle) or anti-CD95 plus $40 \mu \mathrm{M}$ zVAD-fmk (right). (b) Immunoblot analysis for SCL/Tal-1 and GATA-1 of whole-cell lysates from day-7 erythroblasts untreated or treated with anti-CD95 or anti-CD95 plus zVAD-fmk, revealing that proteolysis of SCL/Tal-1 precedes GATA-1 degradation and massive caspase-3 cleavage, as shown by decrease of procaspase-3 levels and formation of active p17 fragment. (c) Quantitative analysis of transcription factor protein levels. Data represent mean \pm s.d. of three independent experiments

resistant SCL/Tal-1. Immunoblot analysis showed that the expression of caspase-resistant SCL/Tal1 was able to prevent GATA-1 downmodulation in CD95-stimulated erythroid cells (Figure $3 d$ ), suggesting that caspase-mediated $\mathrm{SCL} / \mathrm{Tal}-1$ cleavage is required for massive GATA-1 degradation.

To rule out the possibility that SCL D180E/D296E may promote erythroid growth and differentiation by directly targeting caspases, we examined the effect of caspaseresistant SCL on apoptosis of erythroid progenitors induced by chemotherapeutic drugs. Expression of SCL D180E/ D296E did not exert significant protection of erythroid cells from topotecan-induced apoptosis, whereas the caspase inhibitor zVAD-fmk efficiently inhibited drug-induced cell death (Figure 4a). Moreover, enforced expression of caspase-resistant SCL in a CD95-sensitive lymphoblastoid cell 

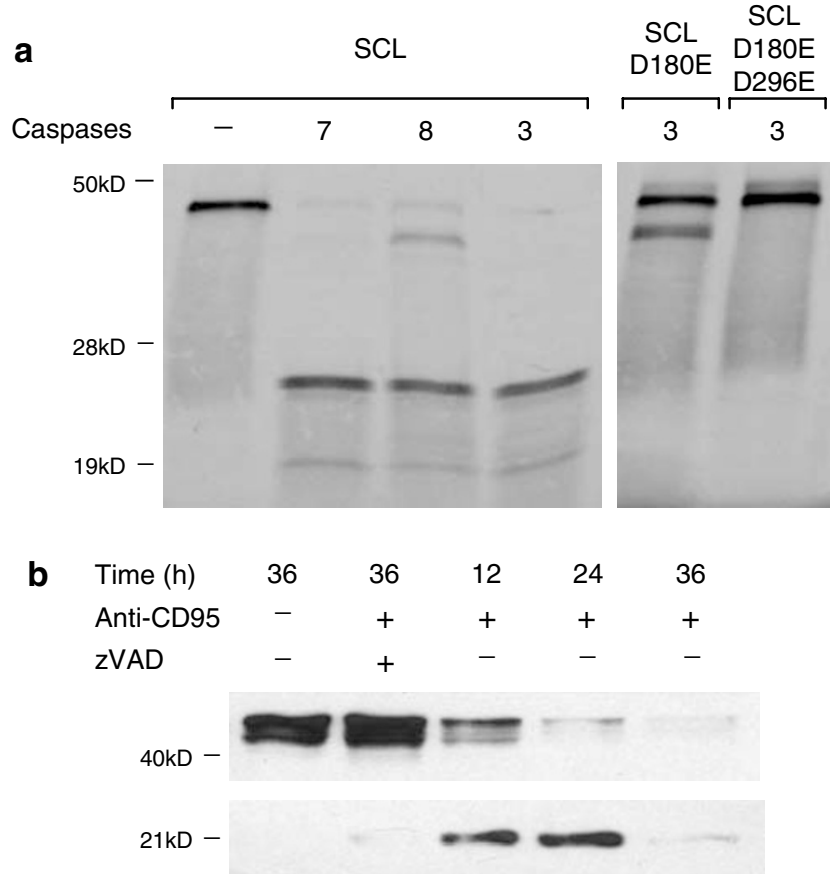

Figure $2 \mathrm{SCL} / \mathrm{Tal}-1$ is cleaved by caspase- $3,-7$, and -8 at Asp180 and Asp296, and the C-terminal fragment is degraded in vivo. (a) In vitro translated $\left.{ }^{35} \mathrm{~S}\right]$ methionine-labelled SCL/Tal-1 was incubated for $1 \mathrm{~h}$ at $30^{\circ} \mathrm{C}$ with reaction buffer alone $(-)$ or with purified caspase-,--8 , or -3 . Partially and completely caspase-resistant SCL/Tal-1 mutants (D180E and SCL D180E D296E, respectively) were exposed to caspase-3 in the same experimental conditions. Samples were analyzed by $12 \%$ SDS-PAGE and autoradiography. (b) Immunoblot analysis of protein lysates from immature erythroblasts stimulated for the times indicated with anti-CD95, or with anti-CD95 plus zVAD-fmk, using an antibody (BTL73) directed to the bHLH domain of SCL/Tal-1

line did not alter sensitivity towards CD95-induced death (Figure $4 b$ ), which was completely prevented by zVAD-fmk. Since inefficient lymphoblast protection from CD95-induced apoptosis could be because of an alternative degradation pathway of SCL D180E/D296E, we analyzed SCL/Tal-1 levels in lymphoblastoid cells transduced with wild-type or mutated SCL/Tal-1 and stimulated with anti-CD95 in the presence or in the absence of zVAD-fmk. Wild-type SCL/Tal-1 was cleaved by caspases in anti-CD95-stimulated lymphoblasts, while its partially and completely caspase-resistant forms were moderately degraded and almost unaffected, respectively (Figure 4c). The fact that CD95-induced apoptosis of lymphoblastoid cells occurs in the presence of high levels of caspaseresistant SCL/Tal-1 indicates that SCL D180E/D296E does not function as a direct inhibitor of caspases. Furthermore, we did not detect by immunoprecipitation experiments any association between SCL D180E/D296E and caspase-3 or 8 in cells unstimulated or stimulated with anti-CD95, while E2A family members were readily coimmunoprecipitated (not shown). Therefore, the ability of the caspaseresistant SCL/Tal-1 mutant to affect the survival and differentiation of erythroid cells likely represents a specific effect of this protein rather than a consequence of generalized caspase inhibition. a
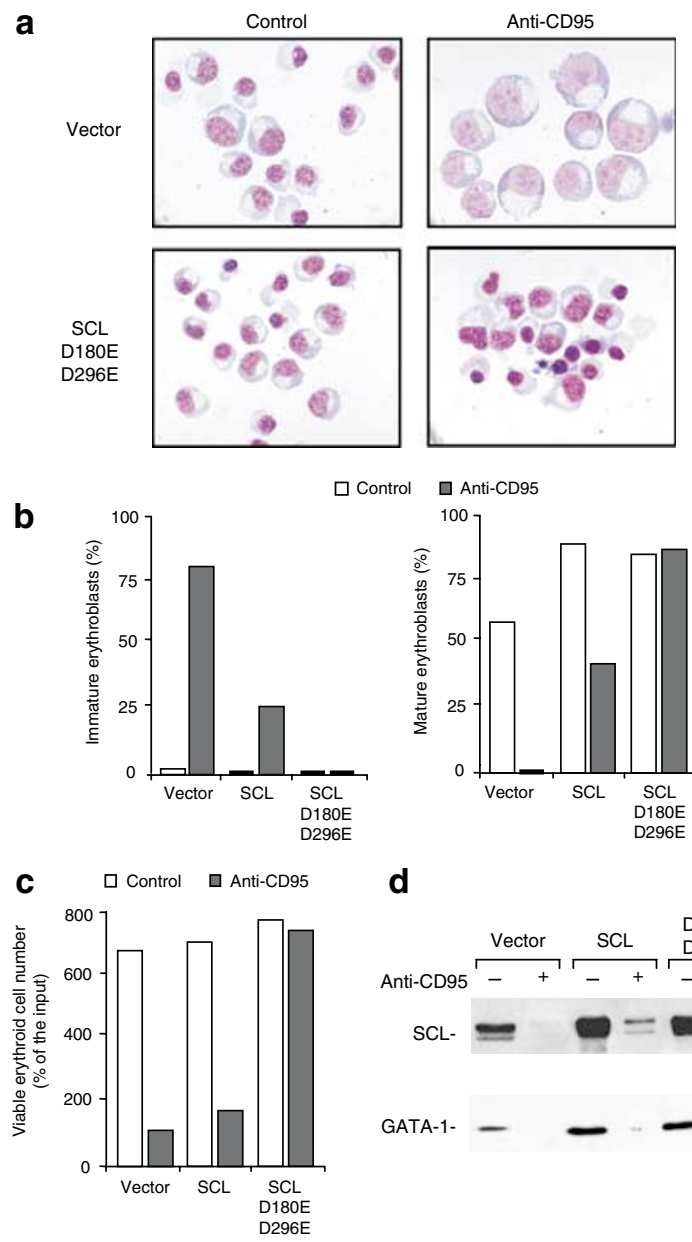

d
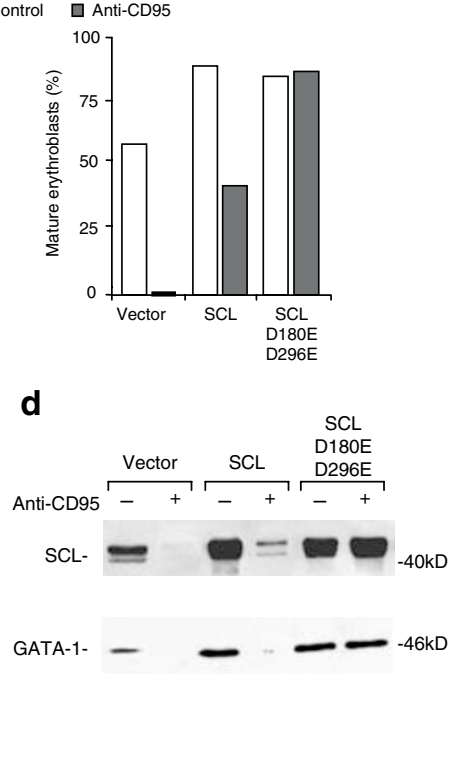

Figure 3 The expression of caspase-resistant SCL/Tal-1 mutant abrogates CD95-mediated erythropoiesis blockade and prevents downmodulation of GATA-1. Effect of SCL D180E/D296E expression on the differentiation (a, b) and expansion (c) of erythroid progenitors exposed to anti-CD95 antibody. $\mathrm{CD}_{3} 4^{+}$cells were cultivated in cycling growth factors for 2 days, subjected to retroviral infection and sorted for comparable expression levels of GFP. Sorted cells were grown in erythroid medium, stimulated with anti-CD95 after 4 days of erythroid differentiation and analyzed on day 8 (a) or day $9(\mathbf{b}, \mathbf{c})$ of culture. Proerythroblasts and basophilic erythroblasts are indicated as immature, orthochromatic erythroblasts as mature cells. (d) Immunoblot analysis of SCL and GATA-1 levels in erythroid progenitors transduced with empty vector, wildtype (SCL) and caspase-resistant SCL/Tal-1 (SCL D180E D296E) and stimulated for 2 days with anti-CD95 where indicated. A representative experiment of five performed is shown

\section{Caspase-resistant SCL/Tal-1 prevents Bcl-xL downmodulation and caspase activation and GATA-1 degradation induced by Epo deprivation in immature erythroblasts}

The level of Epo dictates red cell production through the selective action on erythroid progenitors and precursors. ${ }^{40}$ Epo promotes survival, growth and differentiation of immature erythroblasts, which undergo caspase activation and apoptosis in the absence of this growth factor. ${ }^{3,40}$ To determine whether SCL/Tal-1 is cleaved and degraded in erythroid cells during Epo deprivation, we expressed wild-type and caspaseresistant SCL/Tal-1 in erythroid progenitors and analyzed 
a

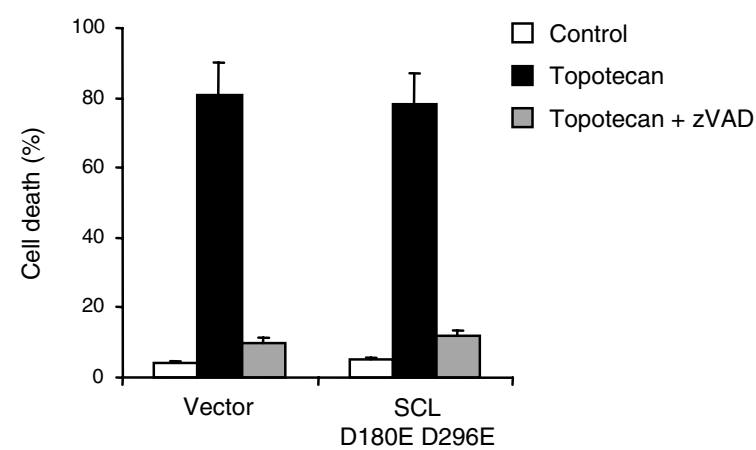

b

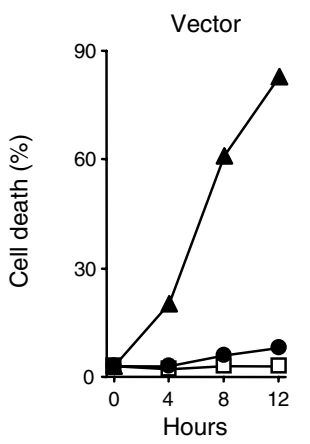

C
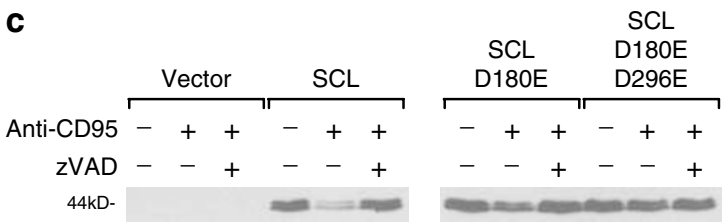

Figure 4 Caspase-uncleavable SCL/Tal-1 is not a general inhibitor of caspase activation. (a) Induction of apoptosis in erythroid precursors derived by CD34 cells and transduced with empty vector or with caspase-resistant SCL/Tal-1 (SCL D180E D296E). After 5 days of erythroid differentiation, cells were treated with $50 \mathrm{ng} / \mathrm{ml}$ topotecan with or without $40 \mu \mathrm{M}$ zVAD-fmk and assayed for viability after $24 \mathrm{~h}$. Data are mean \pm S.D. of three independent experiments. (b) Lymphoblastoid B cells (JY) were transduced with empty vector or SCL D180E/ D296E, treated with anti-CD95 antibody at $100 \mathrm{ng} / \mathrm{ml}$ with or without $\mathrm{ZVAD}$-fmk $40 \mu \mathrm{M}$ and examined $12 \mathrm{~h}$ later for the percentage of cell death. A representative experiment of four performed is shown. (c) Immunoblot analysis of SCLTal-1 levels in JY cells transduced with empty vector, wild-type SCLTal-1 (SCL), partially caspase-resistant SCLTal-1 mutant (SCL D180E) and completely caspase-resistant SCLTal-1 mutant (SCL D180E D296E) and exposed to antiCD95 agonistic antibody in the presence or absence of $40 \mu \mathrm{M}$ zVAD-fmk

erythroid transcription factor levels by immunoblot. Both SCL/ Tal-1 and GATA-1 were degraded in early erythroid precursors after 2 days of culture in the absence of Epo, while GATA-2 levels increased (Figure 5). As for CD95 stimulation, expression of uncleavable SCL/Tal-1 was able to prevent GATA-1 degradation induced by Epo deprivation (Figure 5), again suggesting that $\mathrm{SCL} / \mathrm{Tal}-1$ cleavage lies upstream in the caspase-mediated antierythropoietic process and may be required for GATA-1 processing.

To determine whether differences in caspase activation status may explain the protection exerted by SCL/Tal-1 on GATA-1 levels, we analyzed by immunoblot those caspases involved in GATA-1 cleavage and erythropoietic blockade. ${ }^{3}$ SCL/Tal-1 levels inversely correlated with the degree of caspase activation, as deduced by detection of procaspases

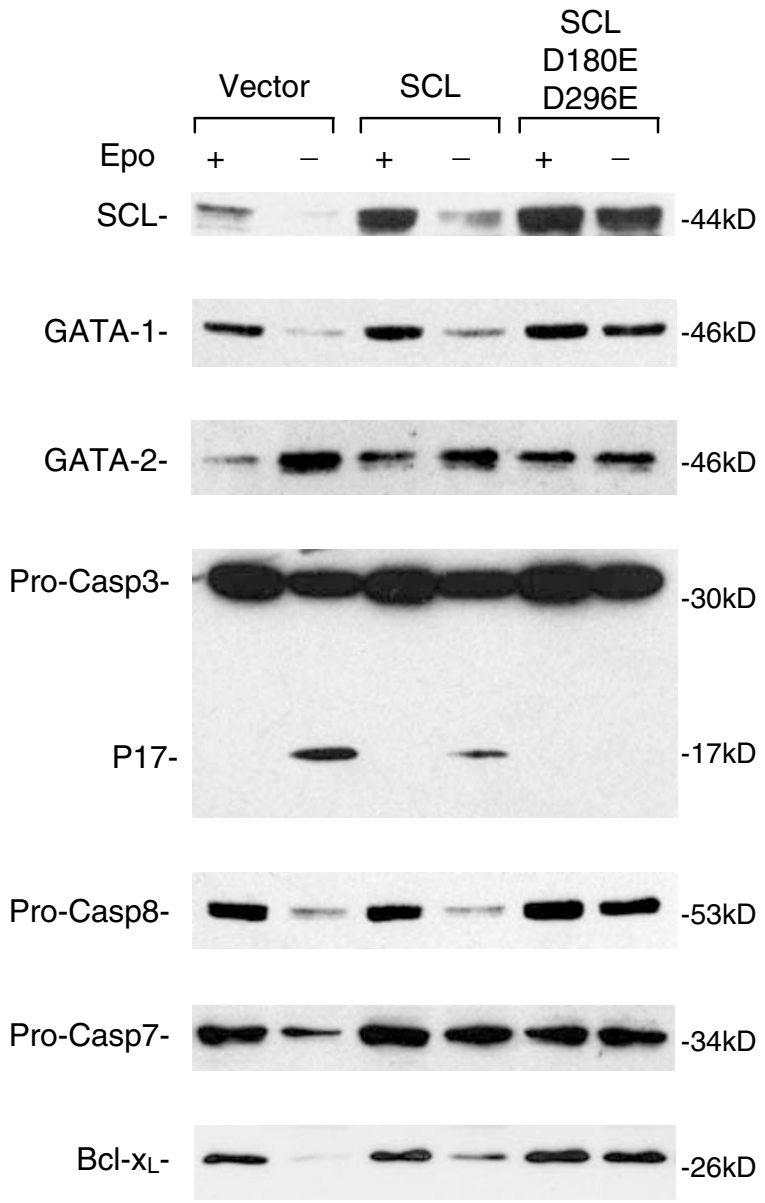

Figure 5 Caspase-uncleavable SCL/Tal-1 maintains high levels of GATA-1 and $\mathrm{Bcl}-\mathrm{X}_{\mathrm{L}}$ and suppresses caspase activation in the absence of Epo. Immunoblot analysis of transcription factors, caspases and $B c-X_{L}$ in day- 6 erythroblasts transduced with vector alone (Vector), wild-type (SCL) or caspaseresistant SCL/Tal-1 (SCL D180E D296E). On day 4 of erythroid culture, cells have been deprived of Epo for 2 days where indicated. A representative experiment of four performed is shown.

and their active fragments (Figure 5). In order to understand the mechanism by which caspase-resistant SCL/Tal- 1 interferes with amplification of the caspase cascade, we explored the possibility that SCL/Tal-1 may influence the levels of Bcl$X_{L}$, which has been shown to play a central role in the survival of immature erythroid cells. Bcl- $X_{L}$ levels were strongly downregulated in Epo-deprived control erythroblasts, and only modestly maintained in cells transduced with wild-type SCL/Tal-1. In contrast, expression of caspase-resistant SCL/ Tal-1 was able to sustain high Bcl- $X_{L}$ levels in the absence of growth factors (Figure 5), providing a possible contribution to the decreased caspase activity observed in these cells.

\section{Caspase-resistant SCL/Tal-1 protects erythroid cells from apoptosis induced by Epo deprivation and allows proliferation of immature erythroblasts in the absence of growth factors}

Since caspase-resistant SCL/Tal-1 prevents amplification of caspase cascade and GATA-1 degradation induced by Epo 

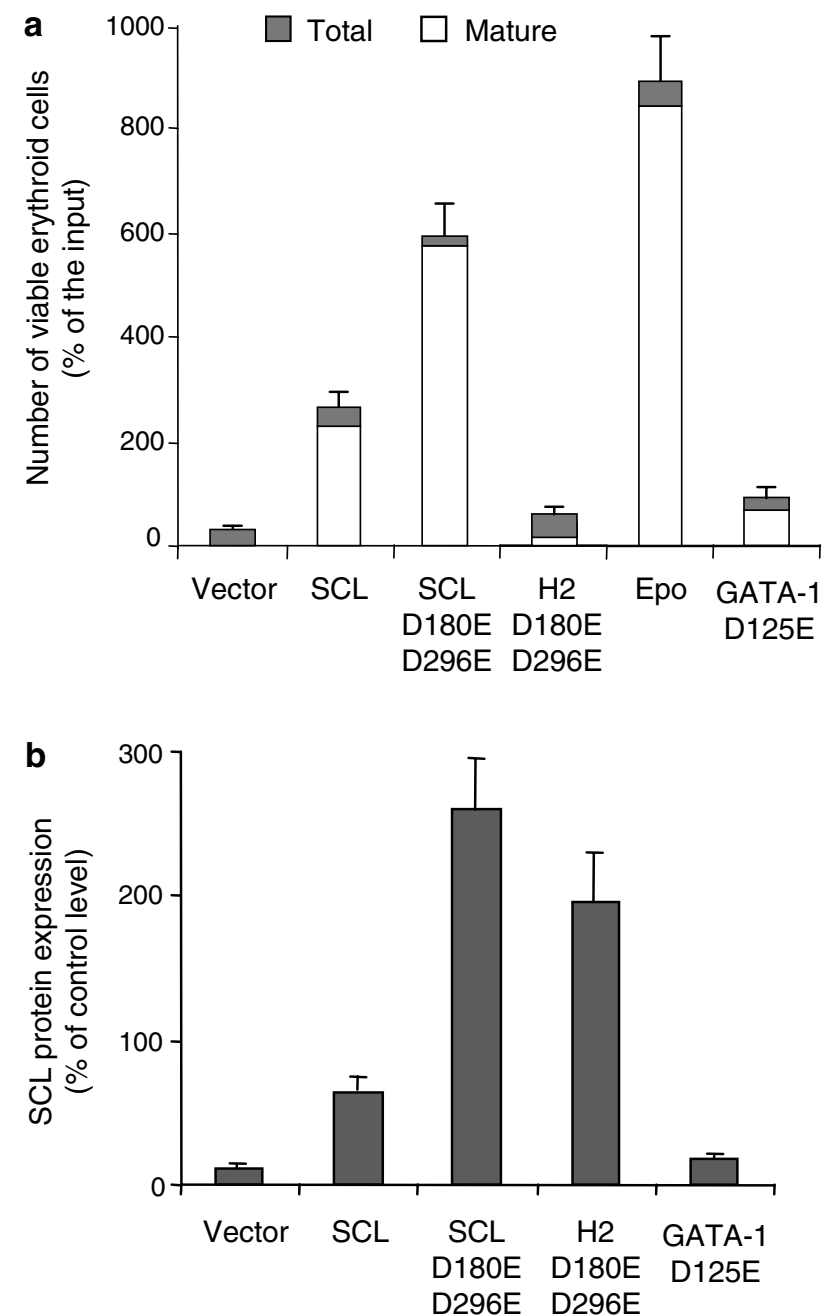

Figure 6 Caspase-uncleavable SCL/Tal-1 allows survival and proliferation of erythroblasts in the absence of Epo through its HLH domain. (a) Erythroid progenitor cells transduced with vector alone, wild-type (SCL), caspase-resistant SCL/Tal-1 (SCL D180E D296E), caspase-resistant HLH mutated SCL/Tal-1 (H2 D180E D296E) and caspase-resistant GATA-1 (GATA-1 D125E) were deprived of Epo on day 4 of erythroid culture and analyzed for cell number and differentiation after 5 days. Control cells (+Epo) have been transduced with empty vector and grown in standard erythroid medium. (b) In the transduced groups analyzed in (a), SCL expression was evaluated by immunoblot after 2 days of Epo deprivation, as compared with Epo supplied cells. Data are mean \pm S.D. of four independent experiments

deprivation, we investigated its capacity to protect erythroid cells from apoptosis. Late erythroid progenitors were cultivated for 5 days in the absence of Epo and examined for cell number and differentiation. As expected, erythroid cell expressing the empty vector died or failed to differentiate in the absence of growth factors. However, the prevention of SCL/Tal-1 downmodulation counteracted the antierythropoietic effects of Epo deprivation and allowed survival, expansion and terminal differentiation of erythroid cells, almost at the levels observed in Epo-supplied cells (Figure 6a). In contrast, an SCL D180E/D296E mutant disrupted in the helix-loophelix (HLH) domain (H2 D180E/D296E) showed substantial inability to increase erythroid survival and differentiation, indicating that the caspase resistance without integrity of the
$\mathrm{HLH}$ domain is not sufficient for promoting terminal erythropoiesis. Importantly, expression of caspase-resistant GATA-1 allowed the survival, but not the expansion, of erythroid cells in the absence of Epo (Figure 6a), suggesting that SCL/Tal-1 is required for effective erythropoiesis and that its activity is not restricted to the protection of GATA-1 degradation. As expected, in the absence of Epo SCL expression decreased in cells transduced with the caspase-resistant GATA-1 mutant. In contrast, the transduction of H2 D180E/D296E was able to maintain high SCL protein levels (Figure $6 b$ ), despite the cleavage of the endogenous protein and the inability of transduced cells to expand and differentiate (Figure $6 a$ and data not shown).

\section{Discussion}

Expansion of the erythroid compartment is controlled by positive and negative signals operating on immature erythroblasts, which are Epo-dependent and highly susceptible to apoptosis. Within the erythroblastic islands of the bone marrow, the interaction between death receptors expressed on the surface of immature erythroblasts with their ligands produced by mature erythroblasts inhibits the growth and differentiation of immature erythroblasts by inducing activation of caspases. ${ }^{2}$ During this process, caspases are responsible for the cleavage of the erythroid transcription factor GATA-1 and determine growth arrest or apoptosis depending on the levels of circulating Epo, which are directly related to the physiological requirement of red cell production. $^{3}$

SCL/Tal-1 has been reported to exert proliferative and antiapoptotic effects on hematopoietic cells and to function as a positive regulator of erythroid differentiation. ${ }^{41-44}$ In the present study, we provide evidence that cleavage of SCL/Tal1 by caspases is a key event in the negative regulation of erythropoiesis, being required for the amplification of caspase activation in erythroid progenitor cells. Comparative kinetic analysis of caspase-3, GATA-1 and SCL/Tal-1 in CD95stimulated erythroblasts revealed that SCL/Tal-1 cleavage occurs during the early phase of death receptor signaling and is almost completed before downregulation of GATA-1 levels. Furthermore, SCL/Tal-1 cleavage precedes massive activation of caspase-3 and concomitant amplification of the caspase cascade, and SCL/Tal-1 levels appear inversely correlated to the intensity of caspase-3 activity. Interestingly, SCL/Tal-1 degradation not only precedes GATA-1 cleavage in the sequence of events that leads to erythropoietic arrest and apoptosis, but also causally determines the extent of GATA-1 downregulation. In fact, overexpression of caspase-uncleavable SCL/Tal-1 in immature erythroblasts prevents GATA-1 degradation induced both by CD95 activation and Epo deprivation, suggesting that SCL/Tal-1 plays a central role in the hierarchy of events that negatively regulate erythroid differentiation.

SCL/Tal-1 is composed of a DNA-binding basic domain and a $\mathrm{HLH}$ domain required for heterodimerization with E2A gene products. The two caspase cleavage sites of SCL/Tal-1 produce a $\mathrm{C}$-terminus fragment containing both the basic and the HLH domain. This potentially active fragment resembles an SCL/Tal-1 variant often expressed in malignant cells, 
which mimics the biological effects of full-length SCL/Tal-1. Since caspase cleavage has been shown in some cases to produce protein fragments with independent biological activity, it is theoretically possible that the cleavage event may produce a functional truncated SCL/Tal-1 molecule or even create an active fragment capable of new transcriptional associations. However, a rapid disappearance of caspaseproduced SCL/Tal-1 fragments occurs during the early phases of caspase activation, possibly as a consequence of proteasome-mediated degradation. Cleaved caspase fragments have been reported to be ubiquitinated by IAP proteins and consequently rapidly targeted to the proteasome. ${ }^{45}$ It can be speculated that the bHLH fragment of SCL/Tal-1 is exposed to ubiquitination and proteasome-mediated degradation either as a consequence of its interaction with caspase active fragments or independently from this association.

Erythroid progenitor cells that overexpress caspase-resistant SCL/Tal-1 are protected from the antierythropoietic and apoptotic effects of growth factor deprivation. Caspase activation is also inhibited in these cells, suggesting that SCL/Tal-1 interferes at some point in the amplification of the caspase cascade. Importantly, this inhibition was not because of a direct association between the mutant SCL/Tal-1 molecule and activated caspases, therefore, excluding the possibility that it acts as an aspecific inhibitor of caspases.

$\mathrm{Bcl}-\mathrm{X}_{\mathrm{L}}$ has been shown to be indispensable for survival and maturation of erythroid cells, as indicated by the fact that Bcl$X_{L}$-deficient mice suffer from severe anemia with large amount of erythroblasts undergoing apoptosis before reaching the final differentiation stage. ${ }^{6,46} \mathrm{Bcl}-\mathrm{X}_{\mathrm{L}}$ antagonizes proapoptotic $\mathrm{Bcl}-2$ family members and contributes to mitochondrial homeostasis through ion channel formation, thus inhibiting cytochrome $c$ translocation, apoptosome formation and activation of executioner caspases. ${ }^{47}$ Erythroblasts expressing caspase-resistant SCL/Tal-1 maintain normal levels of $\mathrm{Bcl}-\mathrm{X}_{\mathrm{L}}$ in the absence of growth factors, thus providing a possible explanation for the decreased caspase activation and for Epo-independent expansion observed in these cells. In line with this interpretation, a recent report has shown that retroviral transduction of $\mathrm{Bcl}-\mathrm{X}_{\mathrm{L}}$ in primary murine erythroblasts allows these cells to undergo terminal maturation in the absence of Epo. ${ }^{48}$ Since GATA- 1 provides an essential contribution to the induction of $\mathrm{Bcl}-\mathrm{X}_{\mathrm{L}}$ expression in developing erythroblasts, ${ }^{4}$ it may be speculated that SCL/Tal1 indirectly maintains $\mathrm{Bcl}-\mathrm{X}_{\mathrm{L}}$ levels by preventing GATA-1 degradation. It remains to be determined whether bcl- $x$ is a transcriptional target of the multifactorial transcriptional complex comprising SCL-Tal-1 and GATA-1, although previous work presented by Gregory et al. ${ }^{4}$ suggests that the effect of GATA-1 on the bcl-x promoter may be indirect.

SCL/Tal-1 forms a multimeric DNA-binding complex with Lim-only proteins, GATA-1 and E2A gene products and participates in the transcriptional regulation of hematopoietic genes. ${ }^{10,49,50}$ Although its DNA-binding activity may be dispensable for terminal erythropoiesis, ${ }^{27} \mathrm{SCL} / \mathrm{Tal}-1$ is able to neutralize $\mathrm{E}$ proteins by forming inactive heterodimers bound through their HLH domains. This mechanism has been clearly documented in T-ALL, where SCL/Tal-1 counteracts growth arrest and apoptosis induced by $\mathrm{E} 12$ and $\mathrm{E} 47 . .^{28,29}$ Moreover, SCL/Tal-1 interacts with LMO2/RBTN2, which potentiates the inhibition of $E$ protein activity and acts as a bridge for the formation of major erythroid transcriptional complexes required for survival and development of erythroid cells. $^{29,49}$ Thus, SCL/Tal-1 activity is not restricted to the protection of GATA-1 degradation, in accordance with the substantial inability of caspase-resistant GATA-1 to restore erythroid cell expansion in the absence of Epo. ${ }^{3}$ In fact, because the caspase-uncleavable form of SCL/Tal-1 promotes not only survival but also proliferation and maturation of Epo-deprived erythroid progenitors, it is likely that SCL/Tal-1 regulates transcriptional events that are necessary for the induction - or derepression - of multiple genes involved in erythroid survival and differentiation.

The finding that SCL/Tal-1 represents a key target of caspases in developing erythroblasts exposed to negative regulatory stimuli extends our knowledge on the mechanisms underlying the regulation of red cell production. The ability of caspases to regulate SCL/Tal-1 protein levels may not be confined to erythroid cells, but may have physiological or pathological relevance in the vascular and hematopoietic systems, where SCL/Tal-1 plays an essential role in development.

\section{Materials and Methods}

\section{Antibodies}

GATA-1 (N1) and GATA-2 (CG2-96) antibodies were from Santa Cruz Biotechnology (Santa Cruz, CA, USA). Anti-SCL 1080 was kindly provided by Dr. R Baer (Columbia University College, New York, USA). Anticaspase-3 (65906E) was from BD Pharmingen (San Diego, CA, USA), anti-caspase 8 (clone 5F7) was from UBI (Lake Placid, NY, USA), anticaspase-7 (clone 51) was from BD Transduction Laboratories (Lexington, KY, USA). Anti-SCL/Tal-1 bHLH antibody BTL73 was a generous gift from Dr. K Pulford.

\section{HPC liquid suspension culture}

Human $\mathrm{CD} 34^{+}$progenitor cells were purified from peripheral blood by positive selection using the midi-MACS immunomagnetic separation system (Miltenyi Biotec, Bergisch Gladbach, Germany) according to the manufacturer's instructions. CD34 ${ }^{+}$progenitors were cultured in serumfree medium in the presence of various recombinant human cytokine combinations. Serum-free medium was prepared as follows: Iscove's modified Dulbecco's medium was supplemented with bovine serum albumin $(10 \mathrm{mg} / \mathrm{ml})$, pure human transferrin $(0.7 \mathrm{mg} / \mathrm{ml})$, human lowdensity lipoprotein $(40 \mu \mathrm{g} / \mathrm{ml})$, insulin $(10 \mu \mathrm{g} / \mathrm{ml})$, sodium pyruvate $\left(10^{-4} \mathrm{~mol} / \mathrm{l}\right)$, L-glutamine $\left(2 \times 10^{-3} \mathrm{~mol} / \mathrm{l}\right)$, rare inorganic elements supplemented with iron sulfate $\left(4 \times 10^{-8} \mathrm{~mol} / \mathrm{l}\right)$ and nucleosides $(10 \mu \mathrm{g} /$ $\mathrm{ml}$ each). For erythroid unilineage culture, serum-free medium was supplemented with $0.01 \mathrm{U} / \mathrm{ml}$ interleukin-3, $0.001 \mathrm{ng} / \mathrm{ml} \mathrm{GM-CSF}$ and $3 \mathrm{U} /$ $\mathrm{ml}$ Epo to induce uncontaminated unilineage erythroid differentiation. ${ }^{3}$ Alternatively, before erythroid unilineage differentiation, $\mathrm{CD} 34^{+}$cells were kept for 2 days in serum-free medium supplemented with cycling mixture (IL-3, IL-6, KL, Flt3 ligand) for retroviral infection. CD95 stimulation was obtained by exposing late erythroid progenitors to $100 \mathrm{ng} / \mathrm{ml}$ anti-Fas agonistic antibody ( $\mathrm{CH} 11$, IgM; UBI, Lake Placid, NY, USA). The percentage of cell death was determined by ethidium bromide/acridine orange staining (working solution: 10 and $3 \mu \mathrm{g} / \mathrm{ml}$, respectively) and fluorescence microscopy analysis. The differentiation stage of erythroid 
precursor cells was evaluated by May-Grünwald-Giemsa staining and cytologic analysis.

\section{Immunostaining and Western blotting}

Immunofluorescence detection of SCL and GATA-2 was performed on cells smeared on glass slides by cytocentrifugation as described. ${ }^{3}$ Briefly, cytospin preparations of the cells were fixed $5 \mathrm{~min}$ in absolute methanol at room temperature and $2 \mathrm{~min}$ in absolute acetone at $-20^{\circ} \mathrm{C}$ and then extensively washed in phosphate-buffered saline (PBS) solution. The cells were then preincubated $10 \mathrm{~min}$ at room temperature with purified human $\operatorname{lgG}(50 \mu \mathrm{g} / \mathrm{ml}$ in PBS containing $2 \mathrm{mg} / \mathrm{ml}$ bovine serum albumin (BSA, Sigma, St. Louis, USA) to reduce nonspecific binding of primary antibodies, washed with PBS and then incubated $30 \mathrm{~min}$ at room temperature with primary antibodies (polyclonal rabbit anti-human Tal-1 diluted $1: 200$ in PBS/BSA, monoclonal rat anti-human GATA-1 diluted $1: 40$ in PBS/BSA and monoclonal mouse anti-human GATA-2, diluted $1: 40$ in PBS/BSA). After extensive washing in PBS, the slides were inoculated with either TRITC-labelled $F\left(a b^{\prime}\right)_{2}$ fragments of affinity-purified goat anti-rabbit IgGs or TRITC-labelled $F\left(a b^{\prime}\right)_{2}$ fragments of affinitypurified goat anti-rat IgGs or TRITC-labelled $F\left(a b^{\prime}\right)_{2}$ fragments of affinitypurified rabbit anti-mouse IgGs (all diluted 1:40 and all purchased from Dako, Copenhagen, Denmark). After extensive washing in PBS, the slides were mounted in antifade glycerol mounting medium (Molecular Probes, Eugen, OR, USA) and examined using a fluorescence Microphot-FXA microscope (Nikon, Melville, NY, USA). Images were collected with a Hamamatsu Color-chilled 3CCD camera (Hamamatsu Italia, Arese, Italy), using the same acquisition time and parameters for every transcription factor examined.

For Western blotting, cell extracts were prepared by resuspending the cell pellets in high-salt $1 \%$ NP40 lysis buffer $(20 \mathrm{mM}$ Tris/ $\mathrm{HCl} \mathrm{pH} 7.2$, $200 \mathrm{mM} \mathrm{NaCl}, 1 \% \mathrm{NP} 40$ ) in the presence of $1 \mathrm{mM}$ phenylmethylsulphonyl fluoride (PMSF) and $2 \mu \mathrm{g} / \mathrm{ml}$ each of leupeptin, aprotinin and pepstatin. Protein concentration of lysates was determined by the Bradford assay (Bio-Rad Laboratories). Proteins were analyzed by the standard immunoblot procedure and visualized by chemiluminescence (SuperSignal West Pico or SuperSignal West Dura, Pierce, Rockford, IL, USA). Image processing and analysis were performed with the NIH IMAGE software version 1.62 (by Wayne Rasband, National Institutes of Health, Research Services Branch, NIMH).

\section{Mutagenesis and in vitro transcription/translation}

Site-directed mutagenesis of SCL (Asp180 $\rightarrow$ Glu) was obtained by using overlapping polymerase chain reaction (PCR) oligonucleotides according to the instructions of Quick Change Site-Directed Mutagenesis kit (Stratagene). The resulting SCL CDNA was subjected to extra rounds of mutagenesis to produce an Asp296 $\rightarrow$ Glu substitution for SCL D180E/ $\mathrm{D} 296 \mathrm{E}$ and Leu229 $\rightarrow$ Pro/Arg230 $\rightarrow$ Pro for H2 D180E/D296E. All nucleotide substitutions were confirmed by sequencing. Wild-type and Asp-mutated SCL proteins were produced in vitro for cleavage assays in the presence of $\left[{ }^{35} \mathrm{~S}\right]$ methionine using the TNT-coupled reticulocyte lysate system (Promega).

\section{Production of recombinant caspases and in vitro cleavage assay}

cDNAs of active human caspase-3, -7, and -8, subcloned in pET21 bacterial expression vectors (Novagen), were expressed in BL21 bacteria and purified on $\mathrm{Ni}^{2+}$ affinity resin. For SCL cleavage assay, $1 \mu \mathrm{l}$ of $\mathrm{SCL}$ translation reaction was incubated with $10 \mathrm{ng}$ of purified caspases in ICE buffer (25 mM HEPES, $1 \mathrm{mM}$ EDTA, 5 mM DTT, 0.1\% CHAPS, pH 7.5) in a final volume of $10 \mu \mathrm{l}$. The reaction was incubated for $1 \mathrm{~h}$ at $37^{\circ} \mathrm{C}$ and terminated by adding Laemmli sample buffer and heating at $100^{\circ} \mathrm{C}$ for $3 \mathrm{~min}$. Samples were subjected to SDS-PAGE and the dried gels were exposed to X-ray film.

\section{Production of retroviral particles and transduction of hematopoietic progenitor cells}

Wild-type and mutated SCL CDNAs were cloned into the PINCO retroviral vector. ${ }^{39}$ The amphotropic packaging cell line Phoenix was transfected by standard calcium-phosphate/chloroquine method, and culture supernatants containing retroviral particles were collected $48 \mathrm{~h}$ after transfection. HPC infection was performed by suspending the cells at $5 \times 10^{4} / \mathrm{ml}$ in the viral supernatant supplemented with cycling mixture. For one cycle of infection, cells were centrifuged at $1800 \mathrm{rpm}$ for $45 \mathrm{~min}$ at $32^{\circ} \mathrm{C}$ and placed back in the incubator for $1 \mathrm{~h}$. Cells were subjected to three infection cycles each day for 2 consecutive days and then cultured in growth medium supplemented with cycling mixture for $48 \mathrm{~h}$ before sorting. GFP-positive cells were separated by flow cytometry using a FACS-Vantage (Becton Dickinson, Omaha, CA, USA). Immediately after sorting, hematopoietic progenitor cells were placed in serum-free medium supplemented with erythroid growth factors. ${ }^{3}$ A similar procedure was employed for expressing wild-type and caspase-resistant SCL/Tal-1 in the B lymphoid JY cells.

\section{Acknowledgements}

We thank R Baer for the 1080 antibody against Tal-1 and K Pulford for BTL73 antibody. AZ is a recipient of an FIRC fellowship. This work is supported by grants from AIRC and Italian Health Ministry.

\section{References}

1. Koury MJ, Sawyer ST and Brandt SJ (2002) New insights into erythropoiesis. Curr. Opin. Hematol. 9: 93-100

2. De Maria R, Testa U, Luchetti L, Zeuner A, Stassi G, Pelosi E, Riccioni R, Felli N, Samoggia P and Peschle C (1999) Apoptotic role of Fas/Fas ligand system in the regulation of erythropoiesis. Blood 93: 796-803

3. De Maria R, Zeuner A, Eramo A, Domenichelli C, Bonci D, Grignani F, Srinivasula SM, Alnemri ES, Testa U and Peschle C (1999) Negative regulation of erythropoiesis by caspase-mediated cleavage of GATA-1. Nature 401: 489493

4. Gregory T, Yu C, Ma A, Orkin SH, Blobel GA and Weiss MJ (1999) GATA-1 and erythropoietin cooperate to promote erythroid cell survival by regulating bcl-xL expression. Blood 94: 87-96

5. Boise LH, Gonzalez-Garcia M, Postema CE, Ding L, Lindsten T, Turka LA, Mao X, Nunez $G$ and Thompson CB (1993) bcl-x, a bcl-2-related gene that functions as a dominant regulator of apoptotic cell death. Cell 74: 597-608

6. Motoyama N, Wang F, Roth KA, Sawa H, Nakayama K, Negishi I, Senju S, Zhang Q, Fujii S and Loh DY. (1995) Massive cell death of immature hematopoietic cells and neurons in Bcl-x- deficient mice. Science 267: 15061510

7. Motoyama N, Kimura T, Takahashi T, Watanabe T and Nakano T (1999) bcl-x prevents apoptotic cell death of both primitive and definitive erythrocytes at the end of maturation. J. Exp Med. 189: 1691-1698

8. Weiss MJ and Orkin SH (1995) Transcription factor GATA-1 permits survival and maturation of erythroid precursors by preventing apoptosis. Proc. Natl. Acad. Sci. USA 92: 9623-9627 
9. Warren AJ, Colledge WH, Carlton MB, Evans MJ, Smith AJ and Rabbitts TH (1994) The oncogenic cysteine-rich LIM domain protein rbtn2 is essential for erythroid development. Cell 78: 45-57

10. Shivdasani RA, Mayer EL and Orkin SH (1995) Absence of blood formation in mice lacking the T-cell leukaemia oncoprotein tal-1/SCL. Nature 373: 432-434

11. Begley CG and Green AR (1999) The SCL gene: from case report to critical hematopoietic regulator. Blood 93: 2760-2770

12. Begley CG, Aplan PD, Davey MP, Nakahara K, Tchorz K, Kurtzberg J, Hershfield MS, Haynes BF, Cohen DI, Waldmann TA et al. (1989) Chromosomal translocation in a human leukemic stem-cell line disrupts the $\mathrm{T}$-cell antigen receptor delta-chain diversity region and results in a previously unreported fusion transcript. Proc. Natl. Acad. Sci. USA 86: 2031-2035

13. Murre C, McCaw PS and Baltimore D (1989) A new DNA binding and dimerization motif in immunoglobulin enhancer binding, daughterless, MyoD, and myc proteins. Cell 56: 777-783

14. Massari ME and Murre $C(2000)$ Helix-loop-helix proteins: regulators of transcription in eucaryotic organisms. Mol. Cell. Biol. 20: 429-440

15. Hsu HL, Wadman I and Baer R (1994) Formation of in vivo complexes between the TAL1 and E2A polypeptides of leukemic T cells. Proc. Natl. Acad. Sci. USA 91: 3181-3185

16. Hsu HL, Huang L, Tsan JT, Funk W, Wright WE, Hu JS, Kingston RE and Baer R (1994) Preferred sequences for DNA recognition by the TAL1 helix-loophelix proteins. Mol. Cell. Biol. 14: 1256-1265

17. Hsu HL, Cheng JT, Chen Q and Baer R (1991) Enhancer-binding activity of the tal-1 oncoprotein in association with the E47/E12 helix-loop-helix proteins. Mol. Cell. Biol. 11: 3037-3042

18. Bash RO, Hall S, Timmons CF, Crist WM, Amylon M, Smith RG and Baer R (1995) Does activation of the TAL1 gene occur in a majority of patients with Tcell acute lymphoblastic leukemia? A pediatric oncology group study. Blood 86 : 666-676

19. Chen Q, Cheng JT, Tasi LH, Schneider N, Buchanan G, Carroll A, Crist W, Ozanne B, Siciliano MJ and Baer R (1990) The tal gene undergoes chromosome translocation in $\mathrm{T}$ cell leukemia and potentially encodes a helixloop-helix protein. EMBO J. 9: 415-424

20. Finger LR, Kagan J, Christopher G, Kurtzberg J, Hershfield MS, Nowell PC and Croce CM (1989) Involvement of the TCL5 gene on human chromosome 1 in Tcell leukemia and melanoma. Proc. Natl. Acad. Sci. USA 86: 5039-5043

21. Aplan PD, Lombardi DP, Ginsberg AM, Cossman J, Bertness VL and Kirsch IR (1990) Disruption of the human SCL locus by 'illegitimate' V-(D)-J recombinase activity. Science 250: 1426-1429

22. Brown L, Cheng JT, Chen Q, Siciliano MJ, Crist W, Buchanan G and Baer R (1990) Site- specific recombination of the tal-1 gene is a common occurrence in human T cell leukemia. EMBO J. 9: 3343-3351

23. Bernard $O$, Guglielmi $P$, Jonveaux $P$, Cherif $D$, Gisselbrecht $S$, Mauchauffe $M$, Berger R, Larsen CJ and Mathieu-Mahul D (1990) Two distinct mechanisms for the SCL gene activation in the $t(1 ; 14)$ translocation of T-cell leukemias. Genes Chromosomes Cancer 1: 194-208

24. Condorelli GL, Facchiano F, Valtieri M, Proietti E, Vitelli L, Lulli V, Huebner K Peschle C and Croce CM (1996) T-cell-directed TAL-1 expression induces Tcell malignancies in transgenic mice. Cancer Res. 56: 5113-5119

25. Aplan PD, Jones CA, Chervinsky DS, Zhao X, Ellsworth M, Wu C, McGuire EA and Gross KW (1997) An scl gene product lacking the transactivation domain induces bony abnormalities and cooperates with LMO1 to generate T-cell malignancies in transgenic mice. EMBO J. 16: 2408-2419

26. Larson RC, Lavenir I, Larson TA, Baer R, Warren AJ, Wadman I, Nottage K and Rabbitts TH (1996) Protein dimerization between Lmo2 (Rbtn2) and Tal1 alters thymocyte development and potentiates $\mathrm{T}$ cell tumorigenesis in transgenic mice. EMBO J. 15: 1021-1027

27. Porcher C, Liao EC, Fujiwara Y, Zon LI and Orkin SH (1999) Specification of hematopoietic and vascular development by the $\mathrm{bH} L \mathrm{H}$ transcription factor $\mathrm{SCL}$ without direct DNA binding. Development 126: 4603-4615

28. Park ST, Nolan GP and Sun XH (1999) Growth inhibition and apoptosis due to restoration of E2A activity in T cell acute lymphoblastic leukemia cells. J. Exp. Med. 189: 501-508

29. Chervinsky DS, Zhao XF, Lam DH, Ellsworth M, Gross KW and Aplan PD (1999) Disordered T-cell development and T-cell malignancies in SCL LMO1 double- transgenic mice: parallels with E2A-deficient mice. Mol. Cell Biol. 19 5025-5035
30. Gering M, Rodaway AR, Gottgens B, Patient RK and Green AR (1998) The $\mathrm{SCL}$ gene specifies haemangioblast development from early mesoderm. EMBO J. 17: 4029-4045

31. Green AR, Lints T, Visvader J, Harvey R and Begley CG (1992) SCL is coexpressed with GATA-1 in hemopoietic cells but is also expressed in developing brain. Oncogene 7: 653-660

32. Pulford K, Lecointe N, Leroy-Viard K, Jones M, Mathieu-Mahul D and Mason DY (1995) Expression of TAL-1 proteins in human tissues. Blood 85: 675-684

33. Condorelli G, Vitelli L, Valtieri M, Marta I, Montesoro E, Lulli V, Baer R and Peschle C (1995) Coordinate expression and developmental role of Id2 protein and TAL1/E2A heterodimer in erythroid progenitor differentiation. Blood 86: 164-175

34. Green AR, DeLuca E and Begley CG (1991) Antisense SCL suppresses selfrenewal and enhances spontaneous erythroid differentiation of the human leukaemic cell line K562. EMBO J. 10: 4153-4158

35. Valtieri M, Tocci A, Gabbianelli M, Luchetti L, Masella B, Vitelli L, Botta R, Testa U, Condorelli GL and Peschle C (1998) Enforced TAL-1 expression stimulates primitive, erythroid and megakaryocytic progenitors but blocks the granulopoietic differentiation program. Cancer Res. 58: 562-569

36. Sanchez MJ, Bockamp EO, Miller J, Gambardella L and Green AR (2001) Selective rescue of early haematopoietic progenitors in Scl(-/-) mice by expressing Scl under the control of a stem cell enhancer. Development 128 : 4815-4827

37. Long Q, Huang $\mathrm{H}$, Shafizadeh E, Liu N and Lin S (2000) Stimulation of erythropoiesis by inhibiting a new hematopoietic death receptor in transgenic zebrafish. Nat. Cell Biol. 2: 549-552

38. Weiss MJ, Keller G and Orkin SH (1994) Novel insights into erythroid development revealed through in vitro differentiation of GATA-1 embryonic stem cells. Genes Dev. 8: 1184-1197

39. Grignani F, Kinsella T, Mencarelli A, Valtieri M, Riganelli D, Lanfrancone L, Peschle C, Nolan GP and Pelicci PG (1998) High-efficiency gene transfer and selection of human hematopoietic progenitor cells with a hybrid EBV/retroviral vector expressing the green fluorescence protein. Cancer Res. 58: 14-19

40. Gregoli PA and Bondurant MC (1997) The roles of $B c l-X(L)$ and apopain in the control of erythropoiesis by erythropoietin. Blood 90: 630-640

41. Aplan PD, Nakahara K, Orkin SH and Kirsch IR (1992) The SCL gene product: a positive regulator of erythroid differentiation. EMBO J. 11: 4073-4081

42. Bernard M, Delabesse E, Novault S, Hermine $O$ and Macintyre EA (1998) Antiapoptotic effect of ectopic TAL1/SCL expression in a human leukemic Tcell line. Cancer Res. 58: 2680-2687

43. Leroy-Viard K, Vinit MA, Lecointe N, Jouault $\mathrm{H}$, Hibner U, Romeo PH and Mathieu-Mahul D (1995) Loss of TAL-1 protein activity induces premature apoptosis of Jurkat leukemic T cells upon medium depletion. EMBO J. 14: 2341-2349

44. Condorelli GL, Tocci A, Botta R, Facchiano F, Testa U, Vitelli L, Valtieri M, Croce CM and Peschle C (1997) Ectopic TAL-1/SCL expression in phenotypically normal or leukemic myeloid precursors: proliferative and antiapoptotic effects coupled with a differentiation blockade. Mol. Cell. Biol. 17: 2954-2969

45. Martin SJ (2002) Destabilizing influences in apoptosis: sowing the seeds of IAP destruction. Cell 109: 793-796

46. Wagner KU, Claudio E, Rucker 3rd EB, Riedlinger G, Broussard C, Schwartzberg PL, Siebenlist U and Hennighausen L (2000) Conditional deletion of the Bcl-x gene from erythroid cells results in hemolytic anemia and profound splenomegaly. Development 127: 4949-4958

47. Martinou JC and Green DR (2001) Breaking the mitochondrial barrier. Nat. Rev. Mol. Cell Biol. 2: 63-67

48. Dolznig H, Habermann B, Stangl K, Deiner EM, Moriggl R, Beug H and Mullner EW (2002) Apoptosis protection by the epo target bcl-x(l) allows factorindependent differentiation of primary erythroblasts. Curr Biol. 12: 1076-1085.

49. Wadman IA, Osada H, Grutz GG, Agulnick AD, Westphal H, Forster A and Rabbitts TH (1997) The LIM-only protein Lmo2 is a bridging molecule assembling an erythroid, DNA-binding complex which includes the TAL1, E47, GATA-1 and Ldb1/NLI proteins. EMBO J. 16: 3145-3157.

50. Vitelli L, Condorelli G, Lulli V, Hoang T, Luchetti L, Croce CM and Peschle C (2000) A pentamer transcriptional complex including tal-1 and retinoblastoma protein downmodulates c-kit expression in normal erythroblasts. Mol. Cell. Biol. 20: $5330-5342$. 